\title{
Alternative Value-at-Risk Models for Options
}

\author{
Alfred Lehar \\ Department of \\ Business Administration \\ University of Vienna \\ Tel: $++43-1-427738077$ \\ Fax: ++43-1-4277 38074 \\ mail: alfred.lehar@univie.ac.at
}

January 10,2000 


\title{
Alternative Value-at-Risk Models for Options
}

\begin{abstract}
Risk management has become an important issue for banks and corporations, not only because of regulation but also because of risk adjusted performance measurement. Value-at-risk has become an industry standard in risk measurement. The aim of this paper is to evaluate the performance of different value-at-risk models and find out the driving factors of model performance. While most previous studies focus on linear positions, this paper investigates the suitability of alternative approaches for positions in stock-options. Risk measurement for options is more complex, since movements in the underlying risk factor (stock-prices) have a non-linear impact on option prices and option prices themselves depend on volatility, which is not directly observable on capital markets. Standard models based on the Black-Scholes analysis and models, that build in the stochastic volatility option pricing model by Hull and White are compared using transaction data the Austrian stock market. It is found that, while the Hull-White model is the only model that passes a proportion of failures test, it substantially underestimates losses in those cases, when the loss exceeds the value-at-risk. Value-at-risk models work better for calls, options with a shorter time to maturity and for at or out of the money options.
\end{abstract}

JEL classification: G28, G13. 


\section{Introduction $^{1}$}

Risk Management is a fast growing industry, spendings by financial firms on enterprise wide risk management were estimated to be 890 million USD in 1998 and expected to reach 2.3 billion USD by $2003 .{ }^{2}$ From the perspective of an economist the importance of risk management is not that obvious. If the Modigliani and Miller (1958) theorem applies or all risks are tradable, a firm has no reason to care about risk management. Froot and Stein (1998) show, that if neither of the above conditions hold, risk management is of value to the firm and that the current risk exposure will have a substantial impact on the firm's future investment decisions. ${ }^{3}$ A correct assessment of risk for different divisions within one firm will also allow the instalment of incentive compatible compensation schemes for divisional managers, as Stoughton and Zechner (1999) point out. ${ }^{4}$

Risk management has also been a focal point of bank regulation, starting in 1993 when the Basle Committee on Banking Supervision released a proposal of capital requirements for covering unexpected losses due to market risk. ${ }^{5}$ Under current regulation ${ }^{6}$ banks are allowed to use their own risk management model to determine capital requirements. These "internal models" are subject to sta-

\footnotetext{
${ }^{1}$ I am very grateful for the helpful comments of Engelbert Dockner, Helmut Elsinger, Stefan Pichler, Martin Scheicher, Günter Strobl and Josef Zechner. Thanks to the Vienna Stock Exchange for providing the necessary data. Support from the Austrian National Bank OeNB, Proj Nr. 6052 is gratefully acknowledged.

${ }^{2}$ Rhode (1998)

${ }^{3} \mathrm{Ahn}$ et al. (1999) model the hedging decision of an institution trying to minimize it's value-at-risk using options

${ }^{4}$ see also Merton and Perold (1993), Kimbal (1997), Kimbal (1998) or James (1996).

${ }^{5}$ see Dewatripont and Tirole (1994), page $56 \mathrm{ff}$

${ }^{6}$ Basle Committee on Banking Supervision (1996)
} 
tistical evaluation and regular audits by bank supervisors. ${ }^{7}$ An adequate risk management model is therefore not only necessary to ensure value improving investment decisions and incentive compatible compensation mechanisms, but also to fulfil regulatory requirements.

The most popular risk management figure is value at risk, defined as the maximum loss, that will not be exceeded with a certain probability $\alpha$ during a given holding period. While the measure is very intuitive in its interpretation, it is not at all uniquely determined how to derive the value-at-risk for a given portfolio. $^{8}$

There is a broad literature on comparing value-at-risk models, but most of them focus on portfolios containing linear securities like cash or stocks. StybloBeder (1995) show the difference between value-at-risk forecasts on a given day, for three selected portfolios. Hendricks (1996) compares different value-at-risk models (MA, EWMA and historical simulation) on a test protfolio of linear positions in the foreign exchange market, Engel and Gizycki (1999) compare a great variety of models using FX-exposures of Australian banks, de Raaij and Raunig (1999) compare a value-at-risk model proposed by Hull and White (1998) to more traditional models also using FX-exposures. Böhmer and Sperlich (1997) have studied linear portfolios in German stocks, Aussenegg and Pichler (1997) have compared different value-at-risk measures for bonds, and Jackson et al. (1997) have compared different $\mathrm{VaR}$ models for bonds, equities, and foreign exchange securities using trading book data of a large bank. Danielsson and de Vries (1997) compare value-at-risk estimates for portfolios in stocks and index options.

\footnotetext{
${ }^{7}$ Marshall and Venkataraman (1997) try to evaluate alternative regulatory regimes from a welfare perspective

${ }^{8}$ see Duffie and Pan (1997), Wilson (1998) or Jorion (1997) for surveys on value-at-risk models.
} 
Studying value-at-risk for options adds another level of complexity, because option returns are non-linear in stock returns and because option prices are also driven by changes in the volatility of the underlying stock, which is not directly obserable. Several models have been proposed and implemented to measure value-at-risk for options. A study by Marshall and Siegel (1997), who compare value-at-risk figures from different software vendors for several classes of financial instruments, shows that options have the highest implementation risk, measured by the standard deviation of value-at-risk figures across the different vendors.

Management, regulators, and professional risk managers face a lot of choices when implementing and testing a risk management framework for derivatives. From the risk managers point of view, risk factors, the mapping method, an appropriate pricing model and a distribution of risk factor returns have to be specified. This paper compares different value-at-risk models for stock options, trying to analyse the driving forces behind a well functioning value-at-risk model. Specifically the following issues are addressed:

The choice of the appropriate risk factors: Models of a single risk factor (that is the underlying stock-price) are compared to models that also include volatility risk as a separate risk factor.

Alternative pricing models: Results from the Black-Scholes model are set in relation to value-at-risk figures based on the Hull and White (1987) option pricing model.

Different Mapping methods: Models using a linear mapping are set in relation to models using full valuation.

In addition to the points above, the issue of testing model performance is considered. From the regulator's and management's perspective, it is important 
to test, whether the value-at-risk figures stemming from the risk management model are representative for the risk in the trading books. For the institutions' management this is necessary to allocate capital properly in order to ensure properly working incentive schemes, the regulator is concerned that enough capital is held by financial institutions to ensure the safety and soundness of the banking sector. Testing a value-at-risk model is however not straightforward. The problem is that the "true risk" of the portfolio is not observable. Alternative testing procedures are presented, each of them highlighting a different aspect. The alternative value-at-risk specifications are evaluated using intra-day data on Austrian stock options. The Austrian market is small but representative for a lot of European markets. While most previous studies on the performance of alternative value-at-risk model focused large markets with high turnover, this paper may also give some insights on the applicability of this concept on markets with low capitalisation and turnover.

The rest of the paper is organised as follows: Section 2 defines a framework for value-at-risk models, section 3 summarises the sample, section 4 describes the examined value-at-risk models, the results are presented in section 5 and in section 6 for the partitioned sample, section 7 concludes.

\section{A general value-at-risk framework}

Let us consider a security with today's price $v_{t} \in \boldsymbol{R}$. The profit or loss until time $\mathrm{t}+1$ is given by $\widetilde{\Delta v_{t}}=\widetilde{v_{t+1}}-v_{t}$. The value-at-risk for a given confidence level $(1-\alpha)$ can then be obtained by solving

$$
\mathbb{P}_{v_{t}}(\widetilde{\Delta v} \leq-\mathrm{VaR})=\alpha
$$

To solve the above equation knowledge of the distribution of price changes is necessary. Since is not always straightforward to specify the distribution for one 
security and since in the case of more securities the joint distribution of price changes is required, most risk management models try to simplify computation by introducing a set of risk factors, that are capable of explaining changes in securities' values. The specification of a value-at-risk framework can be seen as a five step procedure:

Choice of the risk factors: For computational convenience it is often assumed, that changes in securities prices can be explained by changes in some risk factors, e.g. the change in value for each bond is explained by movements in interest rates. Some additional notation is required: Let $f_{t} \in \boldsymbol{R}^{l}$ denote the values of the 1 risk factors at time $t$, and $\widetilde{\Delta f_{t}}=\widetilde{f_{t+1}}-f_{t}$ the vector of changes in risk factors from time $\mathrm{t}$ until $\mathrm{t}+1$.

Choice of a pricing model: When reducing the uncertainty in the economy to a set of risk factors, a pricing model is necessary to explain security prices for the different states of nature, defined by realisations of the risk factors. To formalise this approach, assume that there exists a pricing model $\boldsymbol{R}^{l} \rightarrow \boldsymbol{R}: f \mapsto p(f)$ with the property that

$$
v_{t} \approx p\left(f_{t}\right)
$$

that is explaining the price of the security $v_{t}$ by current values of the underlying risk factors.

Choice of a mapping method: The mapping method tries to explain changes in a security's value $\widetilde{\Delta v_{t}}$ by changes of the underlying risk factors $\widetilde{\Delta f_{t}}$. There are two possible approaches in attacking this problem. The first one, full valuation, uses no additional assumptions but requires extensive computational effort. It follows directly from the specification of the pricing model. The change in the security's price is

$$
\widetilde{\Delta v_{t}}=\widetilde{v_{t+1}}-v_{t} \approx p\left(f_{t}+\widetilde{\Delta f_{t}}\right)-p\left(f_{t}\right)
$$


Since most pricing models are complicated functions, the distribution of $\widetilde{\Delta v_{t}}$ can only be determined by means of a Monte-Carlo simulation.

To reduce computational effort, simpler mapping methods have been proposed and are used in practice. Constructing a Taylor series expansion of equation 3 around the current values of the risk factors $f_{t}$ yields:

$$
\left.\widetilde{\Delta v_{t}} \approx p\left(f_{t}+\widetilde{\Delta f_{t+1}}\right)-p_{j}\left(f_{t}\right)=\left(\frac{\partial p\left(f_{t}\right)}{\partial f}\right) \widetilde{\left(\Delta f_{t+1}\right.}\right)+O(2)
$$

When assuming a linear relationship between changes in the underlying and changes in the derivative security's price, the mapping of a security is given by the vector of partial derivatives of the asset's price with respect to the risk factors times the changes of the risk factors. This is often referred to as the delta-approach.

To capture non-linear relationships between factor and security price changes, it is common practice to include the second order term of the Taylor series expansion, which is referred to as the Delta-Gamma approach. ${ }^{9}$ This extends equation 4 to:

$$
\begin{aligned}
\widetilde{\Delta v_{t}} & \approx p\left(f_{t}+\widetilde{\Delta f_{t+1}}\right)-p_{j}\left(f_{t}\right)= \\
& \left.\left.=\left(\frac{\partial p\left(f_{t}\right)}{\partial f}\right) \widetilde{\left(f_{t+1}\right.}\right)+\frac{1}{2}\left[\left(\widetilde{\Delta f_{t+1}}\right)^{\prime}\left(\frac{\partial^{2} p(f, t)}{\partial f^{2}}\right) \widetilde{\left(f_{t+1}\right.}\right)\right]+O(3)
\end{aligned}
$$

where $\left(\frac{\partial^{2} p(f, t)}{\partial f^{2}}\right)$ is the $l \times l$ matrix of second derivatives of $p$ with respect to the individual risk factors.

Distributional assumptions for factor returns: To compute the value-atrisk a distribution of the risk factors has to be specified. The most common

\footnotetext{
${ }^{9}$ See Estrella (1995) for an interesting discussion on convergence issues of the Taylor series in the case of the Black-Scholes option pricing formula.
} 
assumption is to let the factors be jointly normally distributed. ${ }^{10}$ For computational convenience the means are often assumed to be zero. ${ }^{11}$ Together with a linear mapping, the normal distributed factor returns allow analytical computation of the value-at-risk, which explains the assumption's popularity.

Another very popular setup is to draw realisations of risk factor changes from past, observed factor changes. This historical simulation approach has two main advantages: it allows fat tails and all other characteristic features of financial time series and it is very easy to communicate to senior management. The main disadvantage is, that it relies on past data, which might not be good in describing future risk factor changes.

Value-at-risk computation: Depending on the distribution of $\widetilde{\Delta f_{t}}$ and on the mapping method, it is possible in some cases to calculate the value-at-risk analytically, but in general numerical methods have to be used.

The assumption of normally distributed risk factors and delta-mapping allows a very simple computation of value-at-risk. Let $y$ be the vector of partial derivatives from equation 4 , and assume the risk factors to be jointly normal with zero mean and some covariance matrix $\Sigma_{t}$. Then the value-atrisk is given by:

$$
\mathbb{P}_{f}\left(\widetilde{\Delta f_{t}} \mathrm{y} \leq-\mathrm{VaR}\right)=\alpha
$$

or, when considering, that - because of the distributional assumptions $\widetilde{\Delta f}_{t} \mathrm{y}$ is normally distributed with zero mean and a variance given by $\mathrm{y}^{T} \Sigma_{t} \mathrm{y}$, VaR can be computed directly:

$$
\operatorname{VaR}=-\Phi^{-1}(\alpha) \sqrt{\mathrm{y}^{T} \Sigma_{t} \mathrm{y}}
$$

${ }^{10}$ This approach is also used by RiscMetrics ${ }^{T M}$, see Morgan Guaranty Trust Company and Reuters Ltd. (1996)

${ }^{11}$ See Kupiec (1999) for a discussion of the bias arising from this assumption. 
where $\Phi^{-1}($.$) is the inverse of the distribution function of the standard$ normal distribution.

\section{Sample}

The sample consists of transaction data from options on the most active stock on the Austrian Options and Futures Exchange (ÖTOB) during the observation period: Creditanstalt (CA), Austria's largest bank in the sample period. The sample ranges from January $2^{\text {nd }} 1992$ until May $14^{\text {th }} 1996$ or 1,084 trading days and contains 236,047 trades. Due to different opening hours of the options and the stock-exchange and lack of turnover, I eliminated 67,079 trades, where the corresponding trade in the underlying stock was more than an hour ago. Excluding trades on options with a maturity of less than three days and those trades violating arbitrage bounds, left me with 156,953 trades in 807 different contracts, consisting of 110,905 trades of calls and 46,049 of puts respectively. There were 5 trades on the least liquid day, Nov. $17^{\text {th }} 1994$, and 759 trades on the most active day, July $21^{\text {st }} 1992$.

To compute implied volatilities and option-prices I collected daily data on ATS - VIBOR interest rates with maturities of one day, and one, three, and six months respectively. All dividends are assumed to be known and are taken into account. Volatility estimates are also corrected for dividends and capital measures.

To test the validity of value-at-risk models, realised losses have to be compared to losses predicted by the risk management model. For each traded option on a given day I pick the last trade and calculate the over night profit or loss until the first trade on the next day when holding a short position ${ }^{12}$ in that specific option.

${ }^{12}$ The short position is chosen because of its exposure to Gamma risk. Assuming a linear 
Table 1: Models examined in this paper

\begin{tabular}{|l|c|c|c|c|c|}
\hline Model & $\begin{array}{c}\text { Option } \\
\text { pricing model }\end{array}$ & $\begin{array}{c}\text { Risk } \\
\text { factors }\end{array}$ & Mapping & $\begin{array}{c}\text { Risk factor } \\
\text { disribution }\end{array}$ & $\begin{array}{c}\text { Value-at-risk } \\
\text { computation }\end{array}$ \\
\hline Delta & Black & 1 & linear & normal & analytic \\
\hline Stock-price-sim. & Black & 1 & full valuation & normal & numeric \\
\hline $\begin{array}{l}\text { Stock-volatility } \\
\text { simulation }\end{array}$ & Black & 2 & full valuation & normal & numeric \\
\hline Hull-White & Hull-White & 2 & full valuation & normal & numeric \\
\hline
\end{tabular}

This results in 10,151 over night profit/loss observations during the sample period. There were 9.36 profit/loss observations per day on average with a maximum of 42 and a minimum of 2 . These over night profits or losses are compared to the different value-at-risk measures.

\section{Methodology}

As we saw in section 2, the main determinants of a value-at-risk model are the option pricing model, the choice of the risk factors, the mapping, and the distributional assumptions. Table 1 gives an overview of the models examined in this paper, which will be described in detail in sections 4.1 and 4.2. All value-at-risk figures are computed for a $99 \%$ confidence level and a one day holding period.

The distribution of the risk factors is in all cases normal and its variance will be one of the driving forces of the value-at-risk model. Several possibilities of time-series based models have been proposed to estimate this variance. Four different models have been considered for this paper: a simple moving average model with a rolling time window of 30 days, an exponential moving average relation of option and stock prices, as it is often done in practice, overestimates losses for long positions, but will underestimate losses for short positions. 
(EWMA), a GARCH model, and a stochastic volatility model by Taylor $(1986)^{13}$. Additionally option implied volatilities estimated using a method proposed by Lamoureux and Lastrapes (1993) have been evaluated. It was found, that the simple moving average model and the implied volatilities were dominated by the others, but there could not be found a clear ranking for the remaining three. This is consistent with the findings of Lehar et al. (1998), who analyse volatility predictions for five Austrian stocks. Since no clear ranking could be established, the choice of the volatility model is for this sample of second order compared to the other issues. The results in the rest of the paper are based on the EWMA model, since it is used by many practitioners.

\subsection{Value-at-risk models based on the Black-Scholes frame- work}

Since all options in our sample are American style, the suitability of the BlackScholes option pricing model may be an important determinant of the performance of a value-at-risk model. As an alternative I also considered the binomial model, offering the possibility for early exercise. Even with a high level of numerical precision there was no major improvement relative to the Black-Scholes model.

\subsubsection{Delta normal}

The simplest value-at-risk model is important as a benchmark to compare the other models to. The Delta normal model assumes a linear dependence of stock returns and option price changes. The model fits the five step procedure introduced in chapter 2 in the following way:

\footnotetext{
${ }^{13}$ see Diebold and Lopez (1995) or Palm (1996) for a survey on volatility models
} 
- Only one risk factor $f$, that is the price of the stock, is considered in this model, thus $l=1$.

- The model of Black (1975) is used as pricing model $p(f)$.

- A linear mapping is used as defined in equation 4. The first derivative of the option's price with respect to the underlying stock is the option's delta $\Delta_{t}^{o}$

- The returns on the risk factor are assumed to be conditionally normal distributed with zero mean and some volatility $\sigma_{t}^{f}$, which is estimated using an exponentially weighted moving average (EWMA) ${ }^{14}$.

$$
\widetilde{\Delta f_{t}} \sim N\left(0, \sigma_{t}^{f}\right)
$$

- From equation 1 value-at-risk is then given by

$$
\mathbb{P}_{f}\left(\widetilde{\Delta f_{t}} \Delta_{t}^{o} \leq-V a R\right)=\alpha
$$

or, when taking advantage of the disributional assumption

$$
\operatorname{VaR}_{t}^{\Delta}=\left|\sigma_{t}^{f} \Delta_{t}^{o} \Phi^{-1}(\alpha)\right|
$$

with $f_{t} \quad$ Stock Price at time t

$\sigma_{t}^{f} \quad$ Volatility prediction at time $\mathrm{t}$ for the period up to $\mathrm{t}+1$

$\Delta_{t}^{o} \quad$ Delta of Option o at time t

$1-\alpha \quad$ confidence level

$\Phi($.$) \quad distribution function of the standard normal distribution$

${ }^{14}$ The variance forecast $h_{t}$ for day $t+1$ at day $t$ is given by

$$
h_{t}=(1-\lambda) \sum_{i=0}^{\infty} \lambda^{i} r_{i}^{2}=\lambda h_{t-i}+(1-\lambda) r_{t-1}^{2}
$$

with: $r_{t}$ compound return on day t, i.e. $r_{t}=\ln \left(f_{t} / f_{t-1}\right)$ and $\lambda$ decay factor ( $\lambda$ is set equal to 0.94 here) 
Figure 1: Density function of possible profits/losses for a call option, when stock price changes are assumed to be normal distributed.

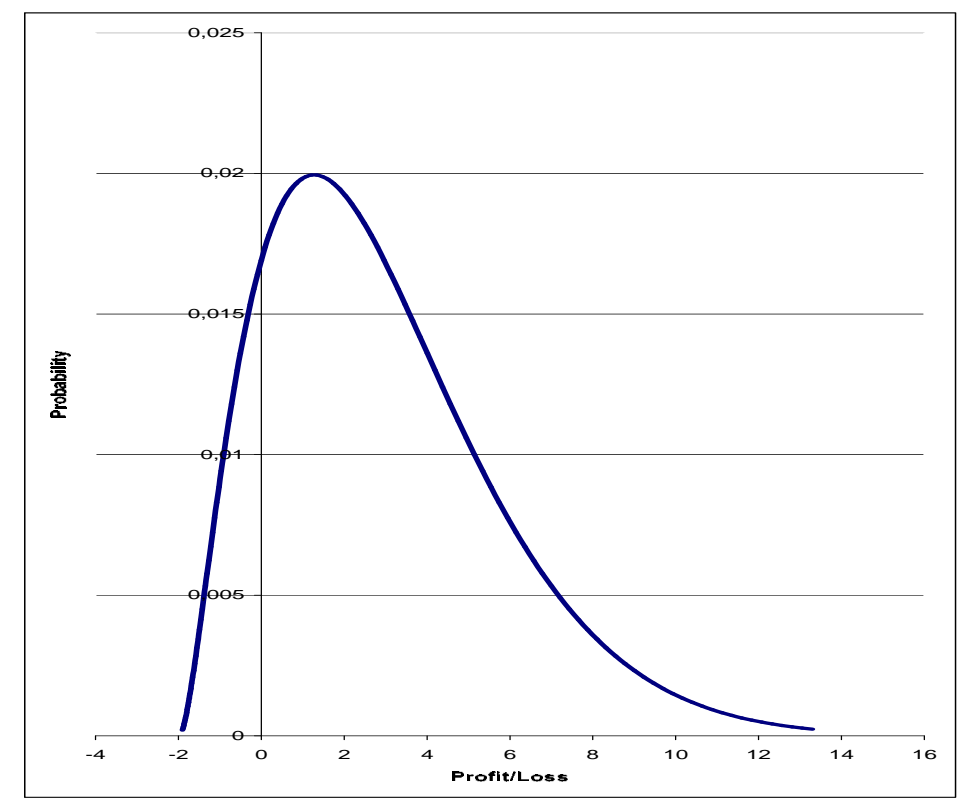

While this approach is simple to implement, it neglects the fact that option prices are non-linear functions of the stock price. Figure 1 shows the profit/loss distribution of an at the money call, with four days to maturity and an implied volatility of $20 \%$ p.a., where stock prices are assumed to be normally distributed with zero mean and a standard deviation of $20 \%$ p.a. Since losses are limited when holding a long position in an option, the distribution is far from a normal distribution. Depending on the moneyness, the time to maturity, and the volatility, the error of the delta-approach is more or less severe. 


\subsubsection{Stock-Price Monte Carlo}

A lot of approximations have been proposed to solve the problem of non-linearity using a second order Taylor series expansion. ${ }^{15}$ Two main problems arise, first that the Taylor series is often not able to capture all non-linearities well enough, especially for the relatively large movements in the stock price, that occur in a risk management setting. Second, the normal distribution of portfolio returns, that makes the delta approach computationally efficient and easy to implement, is lost. Pritsker (1997) compares three approximations with respect to accuracy and computational time to a full-valuation approach as it is done in this paper. His main finding is, that in $25 \%$ of all cases even the best among the approximations, a Monte Carlo simulation using the second order Taylor series, underestimated the true value-at-risk by an average of $10 \%$.

Assuming, that there was no limit on computational time, the full valuation approach implemented in this paper considers all non-linear relationships. Staying within the Black-Scholes framework of constant volatility and stock price movements as the only source of randomness, this approach implements a valueat-risk calculation based on a Monte Carlo simulation. ${ }^{16}$ For each of the 5,000 simulation runs, the assumed process of the stock price within the Black-Scholes framework

$$
d S=\mu S d t+\sigma_{t} S d W
$$

is simulated to compute new possible stock prices for the next trading day. For each of these draws, option prices are computed using the Black-Scholes model

\footnotetext{
${ }^{15}$ See e.g. Jones and Schaefer (1999) or Fallon (1996). A very interesting approach for a stochastic volatility model based on characteristic functions was proposed by El-Jahel et al. (1999). See also Pichler and Selitsch (1999) for a comparison of various approximation methods ${ }^{16}$ See also Broadie and Glasserman (1998) for an interesting introduction on simulation methods for risk management of derivatives
} 
with the new stock price. The value-at-risk is then defined as the $1 \%$-quantile of the simulated distribution of changes in the option price. This approach is consistent with the Black-Scholes model. The differences to the Delta approach are:

- The mapping method is full valuation as in equation 3.

$$
\widetilde{\Delta v_{t}}=\widetilde{v_{t+1}}-v_{t} \approx p\left(f_{t}+\widetilde{\Delta f_{t}}\right)-p\left(f_{t}\right)
$$

- Value-at-risk is then by

$$
\mathbb{P}_{f}\left[\left(p\left(f_{t}+\widehat{\Delta f_{t+1}}\right)-p\left(f_{t}\right)\right) \leq-V a R\right]=\alpha
$$

Since $p($.$) is a non-linear function in the stock price, it is not possible to$ compute the value at risk analytically, instead the distribution has to be approximated using a Monte Carlo simulation.

\subsubsection{Stock and Volatility Simulation}

Even though the Black-Scholes model assumes constant volatility, this is not the case for most financial time series. In the guidelines of the Basle Committee on Banking Supervision (1996) banks are required to hold additional equity to cover possible losses from Vega risk, that is risk of changing volatilities. Including Vega risk cannot be done without violating the Black-Scholes framework, a simple, heuristic approach to integrate volatility risk is presented here.

To quantify volatility risk, I first compute daily changes in the predictions of the EWMA volatility model,

$$
r_{\sigma, t}=\ln \left(\frac{\sigma_{t+1}}{\sigma_{t}}\right)
$$


and second I calculate the sample standard deviation $\sigma_{\sigma}$ of these daily changes $r_{\sigma, t} \cdot{ }^{17}$ This volatility of volatility is $0.10266^{18}$

The value-at-risk is computed via a Monte Carlo simulation, where the stock price is assumed to follow a geometric Brownian motion, and changes in volatility are simulated by draws from a normal distribution with zero mean and standard deviation $\sigma_{\sigma}$. The stock price and volatility movements are assumed to be uncorrelated. New option prices are computed using the Black-Scholes model with the new stock price and the new volatility. The value-at-risk is then again defined as the $1 \%$-quantile of the simulated distribution of changes in the option price. This approach is purely heuristic and is inconsistent with the Black-Scholes framework. Nevertheless it is used by practitioners and it is an important benchmark for the Hull-White model, which includes stochastic volatility in the dynamics of the underlying and thus consistently integrates Vega risk.

To sum up, the model differs from the stock price simulation in the following way:

- There are two risk factors, the stock price and changes in volatility. The dimensionality of the risk factor space $l$ is therefore two.

- The stock price is assumed to follow the process specified in equation 11, with some volatility parameter $\sigma_{t}$, changes in volatility are assumed to be normally distributed with zero mean and standard deviation $\sigma_{\sigma}$. Stock prices and volatility changes are assumed to be uncorrelated.

\footnotetext{
${ }^{17}$ this measure of volatility risk is computed from the whole sample size. The value at risk estimates based on this model thus also use information that was not available at that time. All other value-at-risk models are out-of-sample and only use information that was known at the time of the estimate.

${ }^{18}$ The same procedure applied to a $\operatorname{GARCH}(1,1)$ model yields 0.10528 , for a 30 day moving average the corresponding figure would be 0.09554
} 


\subsection{Value-at-risk models based on the Hull-White model}

\subsubsection{The Hull-White option pricing model}

Hull and White (1987) proposed an option pricing model where both the stock price $S$ and the variance $V$ follow stochastic processes:

$$
\begin{array}{r}
\frac{d S}{S}=\phi d t+\sqrt{V} d z \\
d V=(a+b V) d t+\xi \sqrt{V} d w
\end{array}
$$

Following the article by Corrado and $\mathrm{Su}$ (1998), who calibrate the model to S\&P 500 index options, the parameters are estimated each day by minimising the sum of squared errors between observed and theoretical option prices. The details on the parameter estimation can be found in appendix A.

To have a closer look at the difference between model and market prices, thereby testing whether or not equation 2 holds, parameter estimates are used to forecast each option's price for the next day. These predicted model prices are then compared to observed market prices. ${ }^{19}$ Table 2 lists the mean percentage absolute deviation for the Black-Scholes and the Hull White model. The percentage absolute deviation for trade $i$ is defined by:

$$
P A D_{i}=\frac{\left|c_{m o d}^{i}-c_{m k t}^{i}\right|}{c_{m k t}^{i}}
$$

where

$c_{m o d}^{i} \quad$ price of the option in trade i using model mod

$c_{m k t}^{i} \quad$ observed market price of the option in trade $i$

and the mean PAD is then

$$
M P A D=\frac{1}{n} \sum_{i=1}^{n} P A D_{i}
$$

\footnotetext{
${ }^{19}$ Since no prediction is possible for the first day, the number of trades in table 2 is smaller than in section 3 .
} 
Table 2: Mean percentage absolute deviation for the Black-Scholes and the Hull White model

\begin{tabular}{|l|c|c|c|c|}
\hline \multicolumn{5}{|c|}{ puts and calls (156,854 obs.) } \\
\hline model & MPAD & std.dev(PAD) & $\min (\mathrm{PAD})$ & $\max (\mathrm{PAD})$ \\
\hline Black-Scholes & 0.240 & 0.931 & 00000171 & 73.580 \\
Hull-White & 0.166 & 1.186 & $4.24 \mathrm{e}-06$ & 136.080 \\
\hline \hline \multicolumn{5}{|c|}{ calls (110,813 obs.) } \\
\hline model & MPAD & std.dev(PAD) & $\min (\mathrm{PAD})$ & $\max (\mathrm{PAD})$ \\
\hline Black-Scholes & 0.232 & 0.197 & 0.0000171 & 3.043 \\
Hull-White & 0.150 & 0.616 & $4.24 \mathrm{e}-06$ & 88.561 \\
\hline \hline \multicolumn{5}{|c|}{ puts (46,041 obs.) } \\
\hline model & MPAD & std.dev(PAD) & $\min (\mathrm{PAD})$ & $\max (\mathrm{PAD})$ \\
\hline Black-Scholes & 0.259 & 1.054 & 0.000039 & 73.580 \\
Hull-White & 0.203 & 1.970 & $6.81 \mathrm{e}-06$ & 136.080 \\
\hline
\end{tabular}

where

$n$ number of trades in the sample (here 156854 for puts and calls)

In a study of the German market for interest options, Bühler et al. (1999) find similar mean percentage absolute deviations and also smaller deviations for calls than for puts.

From the risk manager's perspective, the results are not satisfactory. We can see, that the percentage absolute deviation is on average $24 \%$ for the BlackScholes model and 16\% for the Hull-White model. While the Hull-White model fits better on average, the standard deviation of pricing errors is much higher. Overall the assumption of equation 2 that market prices can be explained by model prices seems not to hold too well.

To find out what drives the poor fit of the option pricing models, the absolute pricing errors are regressed on the time to maturity in years, the moneyness of 
Table 3: Results from regression of absolute pricing errors on maturity, moneyness and whether the option is a put or a call.

\begin{tabular}{|l|c|c|c|c|c|}
\hline model & $\begin{array}{c}a_{0} \\
\text { const. }\end{array}$ & $\begin{array}{c}a_{1} \\
\text { maturity }\end{array}$ & $\begin{array}{c}a_{2} \\
\text { moneyness }\end{array}$ & $\begin{array}{c}a_{3} \\
\text { call }\end{array}$ & $R^{2}$ \\
\hline Black-Scholes & 1.7684 & 12.1507 & 0.0934 & -0.1722 & 0.1482 \\
& $(161.61)$ & $(164.21)$ & $(0.93)$ & $(-15.62)$ & \\
\hline Hull-White & 1.4124 & 8.1180 & 10.5259 & -0.1312 & 0.0166 \\
& $(37.04)$ & $(-4.29)$ & $(38.95)$ & $(45.82)$ & \\
\hline
\end{tabular}

t-statistics in brackets

the option ${ }^{20}$, and a binary variable that is set to unity, if the option is a call and to zero in the case of a put:

$$
\left|P E_{i}\right|=a_{0}+a_{1} \text { Time to maturity }+a_{2} \text { Moneyness }+a_{3} \text { Call }
$$

The results in table 3 show, that the pricing error increases with maturity and moneyness and is smaller for calls than for puts. When building a value-at-risk model, we should expect it to work better for calls, out of the money options, and contracts with a short time to maturity. All these issues will be examined in section 6 .

\subsubsection{Value-at-risk calculation using the Hull-White Monte Carlo model}

A simulation is necessary to capture the whole distribution of possible option prices at the next day. For each sample path out of 10,000 simulations, a sequence of random numbers from a bivariate normal distribution with a correlation of $\rho$ and standard deviations of $\sqrt{V}$ and $\xi$ are chosen to simulate the processes in

\footnotetext{
${ }^{20}$ The relation of the option's strike price to the observed stock-price defines the moneyness of the option. For calls this ratio is defined as $m=\frac{\text { stock-price-strike-price }}{\text { strike-price }}$ and $m=\frac{\text { strike-price - stock-price }}{\text { strike-price }}$ for puts.
} 
equations 15 and 16 using an Euler scheme. ${ }^{21}$ New stock prices and volatility levels are used to compute new option prices using the Hull-White model. Profits and losses are sorted and the value-at-risk is determined by the $100^{\text {th }}$ value in this sorted list of losses. ${ }^{22}$

Since the parameters of the Hull-White model are estimated from all observed trades on one day, it is very unlikely that the model price is equal to the observed price of the option. Assuming that the bias, that is the difference between model price and observed price for a given option, will stay constant, profits and losses in the simulation are taken as the difference between the simulated option price and today's model price (instead of today's market price).

The differences to the stock and volatility simulation model of section 4.1.3 are:

- The model of Hull and White (1987) is used as pricing model $p(f)$.

- The risk factors are assumed to follow the dynamics of equation 15 and 16.

\subsection{The Basle approach}

The Basle Committee on Banking Supervision (1996) has proposed a standard methodology for estimating the capital requirements of options, the so called "Delta plus method". Here the capital requirements for the Delta equivalent are equal to $8 \%$ for general market risk $^{23}$, plus a charge for Gamma risk for unanticipated movements of the underlying of $8 \%$, plus an additional charge for

\footnotetext{
${ }^{21}$ see e.g. Kloeden and Platen (1995)

${ }^{22}$ To get the $1 \%$ quantile of 10,000 observations, the $100^{\text {th }}$-highest loss has to be determined.

${ }^{23}$ the required $8 \%$ to cover specific risk are not considered here, since all value-at-risk models focus only on market risk
} 
Volatility changes of $25 \%$. When capital requirements are computed from internal models, the value-at-risk figures must be computed for a ten day holding period and then multiplied by a panic-factor (usually three, except the regulator found an institution's model to perform badly). To level the playing field for internal models and the Basle method, the latter is rescaled to a one day measure without panic factor. The minimum capital requirements are therefore:

$$
\text { Capital }_{t}=\frac{1}{3 \sqrt{10}}\left(S_{t} \Delta_{t} \cdot 0.08+\Gamma_{t}\left(S_{t} \cdot 0.08\right)^{2}+\Lambda_{t} \sigma_{t} \cdot 0.25\right)
$$

where:

$S_{t} \quad$ Stock price at time $\mathrm{t}$

$\Delta_{t} \quad$ Delta of the option an time $\mathrm{t}$

$\Gamma_{t}$ Gamma of the option an time $t$, second partial derivative of option price with respect to the stock price

$\Lambda_{t} \quad$ Vega of the option an time $t$, partial derivative of option price with respect to the volatility

$\sigma_{t}$ implied volatility of the option. 


\section{Empirical results}

Several aspects of performance are relevant for a financial institution when evaluating the performance of a risk management system. First of all, regulatory requirements must be met, but the accuracy and the stability of the value-at-risk approach will be important determinants of model performance. The problem, with testing value-at-risk models is, that there is no clear benchmark, since the true value-at-risk is not known. A variety of different comparisons of the models is presented in the following sections, each of them highlighting a different aspect.

\subsection{Proportion of Failures}

\subsubsection{Likelihood ratio test}

The most important criterion of a risk management system is to fulfil the regulatory requirements. Under current regulation, banks report their value-at-risk figures to the supervisor, who then observes, whether realised losses from trading are above or below the value-at-risk reports. Since value-at-risk is the loss, that will only be exceeded with probability $\alpha$, under the assumption of independence across time, such observations can be modelled as draws from a binomial random variable, where the probability of realising a loss greater than the value-at-risk is equal to $\alpha$. The Basle Committee on Banking Supervision proposed a binomial test to verify accuracy of internal models for capital requirements. Following Kupiec (1995), I implemented the more powerful likelihood ratio test. The test statistic is given by:

$$
L R=-2 \ln \left(\left(1-\alpha^{*}\right)^{(n-x)}\left(\alpha^{*}\right)^{x}\right)+2 \ln \left(\left(1-\frac{x}{n}\right)^{(n-x)}\left(\frac{x}{n}\right)^{x}\right)
$$

where $\alpha^{*}$ is the probability of failure under the null hypothesis, $n$ is the sample size and $x$ is the number of failures in the sample. A failure is defined as an 
observation, where the realised loss exceeds the value-at-risk.

However, as Kupiec (1995) pointed out, even this test is of poor power when used on small or medium size samples. ${ }^{24}$ The table below shows acceptance regions for a sample of 255 observations (1 year) and 10,151, the observations in the sample. All test statistics are evaluated at a $5 \%$ confidence level under the assumption that values-at-risk are computed at the $99 \%$-level, that is $\alpha^{*}=0.01$. The last two columns shows the probability of a type II error, that is falsely accepting a wrong model, a very important issue for regulators. The numbers show the probability of accepting a model as a $99 \%$ value-at-risk model $\left(\alpha^{*}=0.01\right)$, when the true rate of failure $\alpha$ is equal to 0.011 and 0.015 respectively. ${ }^{25}$

\begin{tabular}{|l|c|r|r|}
\hline $\begin{array}{l}\text { Number } \\
\text { of observations }\end{array}$ & $\begin{array}{c}\text { acceptance } \\
\text { region }\end{array}$ & $\begin{array}{r}\text { Type II error rate } \\
(\alpha=1.1 \%)\end{array}$ & $\begin{array}{r}\text { Type II error rate } \\
(\alpha=1.5 \%)\end{array}$ \\
\hline 255 & $x \leq 7$ & $97.61 \%$ & $90.83 \%$ \\
10151 & $83 \leq x \leq 121$ & $82,59 \%$ & $0.48 \%$ \\
\hline
\end{tabular}

Due to the large sample size, results regarding the performance of different value-at-risk methods from this test are by far more robust than results from the typical sample size of the Basle test.

The results of the proportions of failure test are presented in table 4. Only the Hull-White model would be accepted by regulators. All models based on the Black-Scholes framework fail, because they underestimate risk. ${ }^{26}$ Within the Black-Scholes class of models, the Delta-model performs worst, indicating that the non-linearities are of importance. The standard method according to the

\footnotetext{
${ }^{24}$ see also Jorion (1996)

${ }^{25}$ The true rate of failure may be different from the target level, because of model misspecification or a bank trying to lower its capital requirement by lowering its confidence level.

${ }^{26}$ Other volatility models would not significantly increase the model's performance. E.g. the percentage rate of failures for the stock-price simulation approach varies from $2.58 \%$ (implied volatilites) to $1.87 \%$ (GARCH). Similar ranges can be found for the other mapping models.
} 
Table 4: Proportion of failures and descriptive statistics

\begin{tabular}{|l|r|r|r|r|r|}
\hline model & \multicolumn{3}{|c|}{ value-at-risk } & \multicolumn{2}{c|}{ failures } \\
& min. & max. & avg. & total & percent \\
\hline Delta & 0.44 & 243.56 & 10.14 & 347 & $3.42 \%$ \\
\hline Stock-Price MC & 0.66 & 348.47 & 12.48 & 222 & $2.19 \%$ \\
\hline Stock and Vola MC & 1.59 & 296.56 & 13.21 & 145 & $1.43 \%$ \\
\hline Hull-White MC & 0.11 & 219.78 & 15.71 & 103 & $1.01 \%$ \\
\hline Basle & 0.25 & 9.26 & 3.72 & 1,733 & $17.07 \%$ \\
\hline
\end{tabular}

Basle committee, when properly rescaled, significantly underestimates capital requirements. ${ }^{27}$

\subsection{Distribution Test}

The problem with the proportion of failures test is, that the information of a predicted distribution of portfolio losses is reduced to a binary variable. Whether the observed loss was close to the value-at-risk or far away is of no importance. To overcome this problem Crnkovic and Drachman (1996) proposed a test based on the distribution of returns, as they are predicted by the risk management model. As outlined in equation 1 the value-at-risk can be obtained by solving

$$
\mathbb{P}_{v_{t}}(\widetilde{\Delta v} \leq-\mathrm{VaR})=\alpha
$$

or equivalently

$$
\alpha=\Phi_{v}(-V a R)
$$

\footnotetext{
${ }^{27}$ The capital requirements of the Basle method will be higher, when the financial institution has exposures in more than one market since it does not allow to take any diversification benefits across markets into account.
} 
Figure 2: Histogram of the percentiles of the realized losses under the distribution from the Hull-White model. The classes in the histogram have a width of 0.05 and are plotted against the density of the uniform distribution

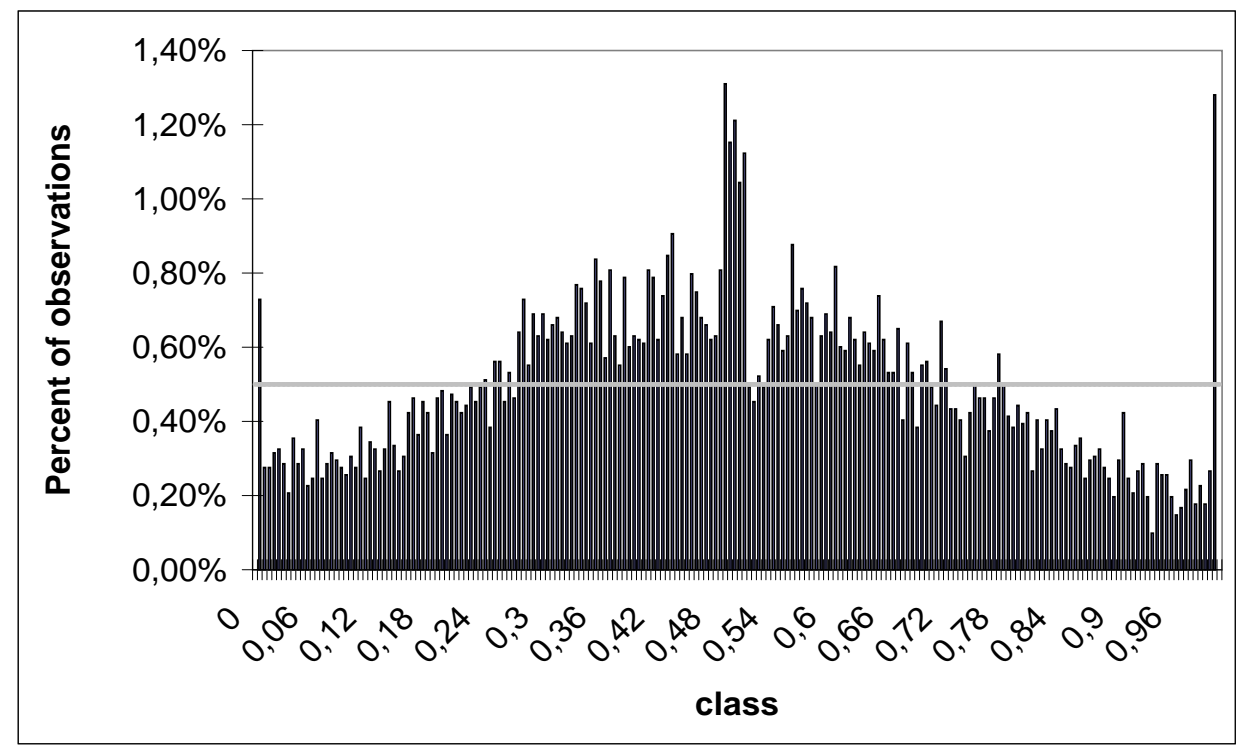

where $\Phi_{v}(z)$ is the cumulative distribution function of portfolio returns for given distributional assumptions about the asset returns. Since realised returns $\varphi$ should just be random draws from this distribution, the according percentiles

$$
\pi=\Phi_{f}(\varphi)
$$

should be uniformly distributed over the unit interval. ${ }^{28}$

Figure 2 shows the histogram of the percentiles $\pi$ from equation 24 plotted against the expected uniform distribution for the Hull-White model. The plots for all models can be found in appendix B. All distributions differ from the uniform distribution in two respects: fat tails and a higher number of observations in the middle. The fat tails show that there are more large losses and gains observed

\footnotetext{
${ }^{28}$ This transformation was proposed by Rosenblatt (1952).
} 
Figure 3: Cumulative distribution function of the Hull-White model, plotted against the uniform distribution.

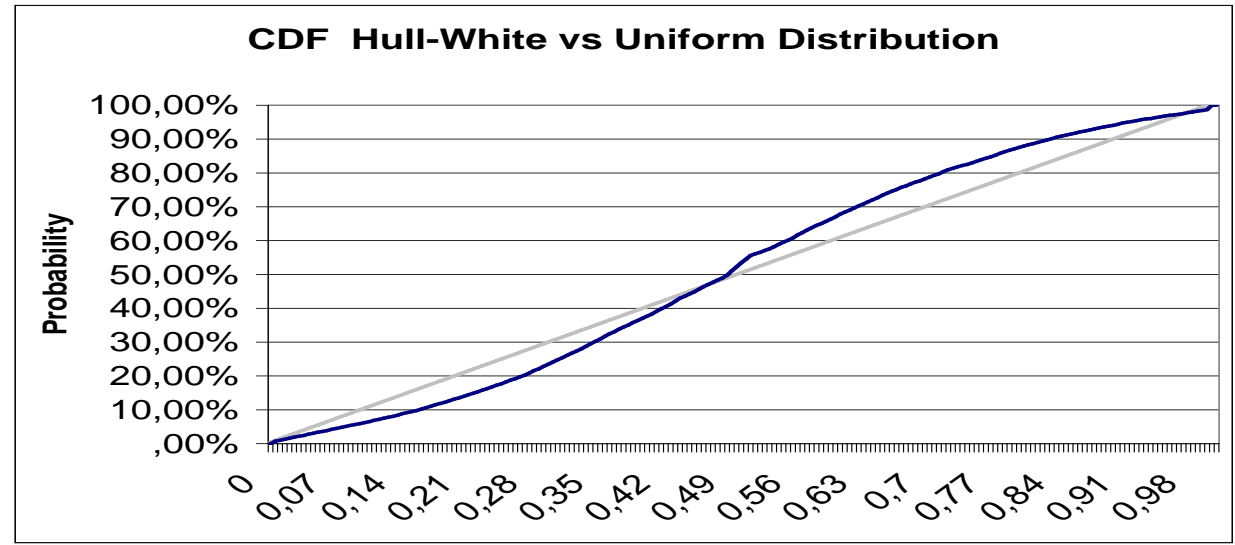

than predicted by the risk management model. This, together with the higher mass in the middle of the histogram, shows that all models are not able to capture the leptocurtic characteristic of security returns.

To determine the deviation from the uniform distribution, Crnkovic and Drachman (1996) proposed a test based on the Kupier statistic, which measures the deviation between two cumulative distribution functions. ${ }^{29}$ As an example, figure 3 shows the cummulative distribution function of the Hull-White model. Let $D(x)$ be the cumulative distribution function of the observed percentiles, then the Kupier statistic is given by:

$$
K=\max _{0 \leq x \leq 1}(D(x)-x)+\max _{0 \leq x \leq 1}(x-D(x))
$$

and the distribution of $K$ for $n$ observations is given by ${ }^{30}$ :

$$
\mathbb{P}(k>K)=G\left(\left[\sqrt{n}+0.155+\frac{0.24}{\sqrt{n}}\right] K\right)
$$

\footnotetext{
${ }^{29}$ see also Lopez (1996)

${ }^{30}$ see e.g. Press et al. (1992), page 627
} 
Table 5: Kupier statistic for the models under the null-hypothesis, that the distribution is uniform, $(99.9 \%$ critical value is 0.02282$)$

\begin{tabular}{|l|r|}
\hline Model & Kupier-Statistic \\
\hline Delta & 0.06551 \\
\hline Stock-Price MC & 0.05605 \\
\hline Stock and Vola MC & 0.13930 \\
\hline Hull-White MC & 0.15887 \\
\hline
\end{tabular}

where

$$
G(\lambda)=2 \sum_{j=1}^{\infty}\left(4 j^{2} \lambda^{2}-1\right) e^{-2 j^{2} \lambda^{2}}
$$

For a sample of 10,151 observations as it is used here in this paper, the critical values are $0.017315,0.0198288$, and 0.02282 for a confidence level of $95 \%, 99 \%$, and $99,9 \%$ respectively. For the Kupier statistic to work, it is necessary to have a large number of observations, a requirement that is satisfied with the sample in this paper.

The test results in table 5 show that the null hypothesis of uniform distribution is rejected at a level of more than $99,9 \%$ for all models.

An extension of the testing procedure above was proposed by Berkowitz (1998). Let $\Phi_{n}^{-1}($.$) be the inverse of the standard normal distribution. Then the$ uniformly distributed percentiles $\pi$ can be transformed into $\mathrm{N}(0,1)$ distributed observations $z=\Phi_{n}^{-1}(\pi)$. This adds no new information, but it enables us to use the likelihood-ratio testing framework. The analogue to the Kupier statistic would be a test of mean zero and variance one. Let the log-likelihood function be:

$$
L\left(\mu, \sigma^{2}\right)=-N \ln (2 \pi)-N \ln \left(\sigma^{2}\right)-\sum_{j=1}^{N} \frac{\left(z_{j}-\mu\right)^{2}}{2 \sigma^{2}}
$$


Table 6: Likelihood ratio test statistic for the models and p-values, under the null hypothesis of zero mean and unit variance

\begin{tabular}{|l|r|r|}
\hline Model & LR-statistic & P-value \\
\hline Delta & 157.92 & $5.1 \mathrm{E}-35$ \\
\hline Stock-Price MC & 115.11 & $1.0 \mathrm{E}-25$ \\
\hline Stock and Vola MC & 378.15 & $7.7 \mathrm{E}-83$ \\
\hline Hull-White MC & 273.44 & $4.2 \mathrm{E}-60$ \\
\hline
\end{tabular}

where $N$ is the number of observations ( $N=10,151$ in our sample).

Then, given sample mean $\hat{\mu}$ and sample standard deviation $\hat{\sigma}$, the appropriate test statistic for testing $\mu=0$ and $\sigma=1$ is given by:

$$
L R=-2\left(L(0,1)-L\left(\hat{\mu}, \hat{\sigma}^{2}\right)\right)
$$

Under the null hypothesis, the test statistic is distributed $\chi^{2}(2)$, chi-squared, with two degrees of freedom.

The results are presented in table 6. All models are rejected at a confidence level far beyond $99,99 \%$.

Both test procedures above, the Kupier statistic and the previous likelihood ratio test focus on the fit of the whole distribution of returns. But management and to regulators will care more about the fit in the left tail, that is the fit of the distribution in those cases, when value-at-risk underestimates the losses. As Berkowitz (1998) shows, the likelihood ratio test for a truncated normal provides the adequate statistic. Let $L^{\prime}$ be the log-likelihood function:

$$
L^{\prime}\left(\mu, \sigma^{2}\right)=-N \ln (2 \pi)-N \ln \left(\sigma^{2}\right)-\sum_{j=1 ; \xi_{j}<V a R_{j}}^{N}\left[\frac{\left(z_{j}-\mu\right)^{2}}{2 \sigma^{2}}-\ln \left(\Phi \frac{\alpha-\mu}{\sigma}\right)\right]
$$


Table 7: Likelihood ratio test statistic for the models and p-values, under the null hypothesis of zero mean and unit variance

\begin{tabular}{|l|r|}
\hline Model & LR'-statistic \\
\hline Delta & 5860.99 \\
\hline Stock-Price MC & 3186.57 \\
\hline Stock and Vola MC & 4013.51 \\
\hline Hull-White MC & 3073.10 \\
\hline
\end{tabular}

Then the appropriate test statistic for testing $\mu=0$ and $\sigma=1$ is given by:

$$
L R^{\prime}=-2\left(L^{\prime}(0,1)-L^{\prime}\left(\hat{\mu}, \hat{\sigma}^{2}\right)\right)
$$

Under the null hypothesis, the test statistic is again distributed $\chi^{2}(2)$, chisquared, with two degrees of freedom.

The results are presented in table 7 . All models are rejected at a confidence level numerically indistinguishable from one.

\subsection{Mean Relative Bias}

Following Hendricks (1996) I adopt this and the following five procedures to compare the relation of the different value-at-risk estimates to each other. To get the first measure, the mean relative bias, I average the value-at-risk figures for each observation and compute the percentage difference between the value-atrisk of each approach and the average risk measure. Table 8 reports the average, minimum, and maximum of these relative biases across all observations in the sample. This measure provides information on the relative size of a particular value-at-risk measure compared to the average. Given $N$ value-at-risk models, let $V a R_{i t}$ be the value-at-risk computed by model $i$ for observation $t$, then the 
relative bias for this observation is given by:

$$
R B_{i t}=\frac{V a R_{i t}-\overline{V a R_{t}}}{\overline{V a R_{t}}}
$$

where $\overline{V a R_{t}}=\frac{1}{N} \sum_{i=1}^{N} V a R_{i t}$. Table 8 reports the average $R B_{t}$ over all t, $\min _{t}\left(R B_{t}\right)$ and $\max _{t}\left(R B_{t}\right)$.

Table 8: Mean relative bias across value-at-risk models

\begin{tabular}{|l|r|r|r|}
\hline model & average & $\min$ & $\max$ \\
\hline Delta & -0.138 & -0.939 & 0.505 \\
\hline Stock-Price MC & 0.046 & -0.922 & 1.499 \\
\hline Stock and Vola MC & 0.195 & -0.824 & 1.785 \\
\hline Hull-White MC & 0.531 & -0.992 & 3.652 \\
\hline Basle & -0.634 & -0.990 & 0.175 \\
\hline
\end{tabular}

As can be seen in Table 8, the Delta and especially the Basle method are generally downward biased, while the Hull-White model is upward biased. On average the Basle model predicts value-at-risks that are only $37 \%$ of the average across all models. Value-at-risk estimates also vary a lot across models, the HullWhite model has the highest variability relative to the other models. For every model at least one trade can be found, where it computes a value-at-risk figure that is more than $80 \%$ below average. There are trades, where the Hull-White Monte Carlo approach yields a value-at-risk measure that is more than 3.5 times as high as the average of all models for that trade.

\subsection{Multiple needed to attain desired coverage}

This performance criterion shows the multiple that would be required for the different risk measures to pass the regulator's proportion of failures test, as shown in section 5.1, at the least possible cost. The multiple is therefore chosen to 
produce 121 failures (the maximum amount tolerated by regulators) in the given sample size.

When using the Basle method, a multiplier of more than 3.5 of the allocated capital would be required to pass the standard test for internal models. The valueat-risk figures of the Delta model, the simplest one of all models considered, must be increased by $44 \%$ to pass the test, which is well below the Basle "panic-factor" if $300 \%$.

\subsection{Average and maximum multiple of tail event to risk measure}

When choosing a risk measure, it is interesting to know what happens if the market moves more than predicted by the risk management system. Dividing the loss in such a tail event, where the loss exceeds the value-at-risk, through the value-at-risk gives the multiple for a given failure, indicating the degree of loss-underestimation, conditional on a failure. Average and maximum multiples across failures are presented in table 10.

Even though the Hull White model performs well on behalf of the proportion of failures test in section 5.1, it substantially underestimates risk in the case of

Table 9: Multiple needed to attain desired coverage

\begin{tabular}{|l|r|}
\hline & multiple needed \\
\hline Delta & 1.442 \\
\hline Stock-Price MC & 1.210 \\
\hline Stock and Vola MC & 1.051 \\
\hline Hull-White MC & 0.952 \\
\hline Basle & 3.551 \\
\hline
\end{tabular}


a tail event. For one put option, the realised loss was more than twelve times higher than the value-at-risk prediction from the Hull-White model. This put has a time to maturity of 35 days, a strike price of 500, and was traded at two consecutive trading days as follows:

\begin{tabular}{|l|r|r|}
\hline date & Dec. 15. 1995 (fr) & Dec. 18. 1995 (mo) \\
\hline time & $10: 54: 58$ & $9: 49: 52$ \\
\hline stockprice & 542 & 529 \\
\hline implied volatility & $28.18 \%$ & $28.13 \%$ \\
\hline price of the option & 4.00 & 5.90 \\
\hline value-at-risk (Hull-White) & 0.149 & \\
\hline
\end{tabular}

The option is deep out of the money and the 2,5\% drop in the stock price results in a $47 \%$ increase of the option's price. The implied volatility stayed constant, showing that Vega risk is not driving the loss. The implied parameters of the Hull-White model on that day (Dec. 15) show a high positive correlation between stock price changes and volatility changes. This positive correlation is the main reason for the Hull-White model's bad performance on that day. Within the Monte Carlo simulation those runs covering declines in the stock price, and thereby increasing the option's price, also show declining volatility, bringing the price back down again. The latter effect is also increased as the option's Vega grows as the stock price approaches the strike. Thus, because of the high positive correlation between stock price and volatility changes, the Monte

Table 10: Average and maximum multiple of tail event to risk measure

\begin{tabular}{|l|r|r|}
\hline model & average multiple & maximum multiple \\
\hline Delta & 1.523 & 5.980 \\
\hline Stock-Price MC & 1.518 & 5.531 \\
\hline Stock and Vola MC & 1.432 & 3.972 \\
\hline Hull-White MC & 1.871 & 12.770 \\
\hline Basle & 2.001 & 13.484 \\
\hline
\end{tabular}


Figure 4: Density functions of Delta-Normal and Hull-White estimated losses for OTM Put on Dec. 15

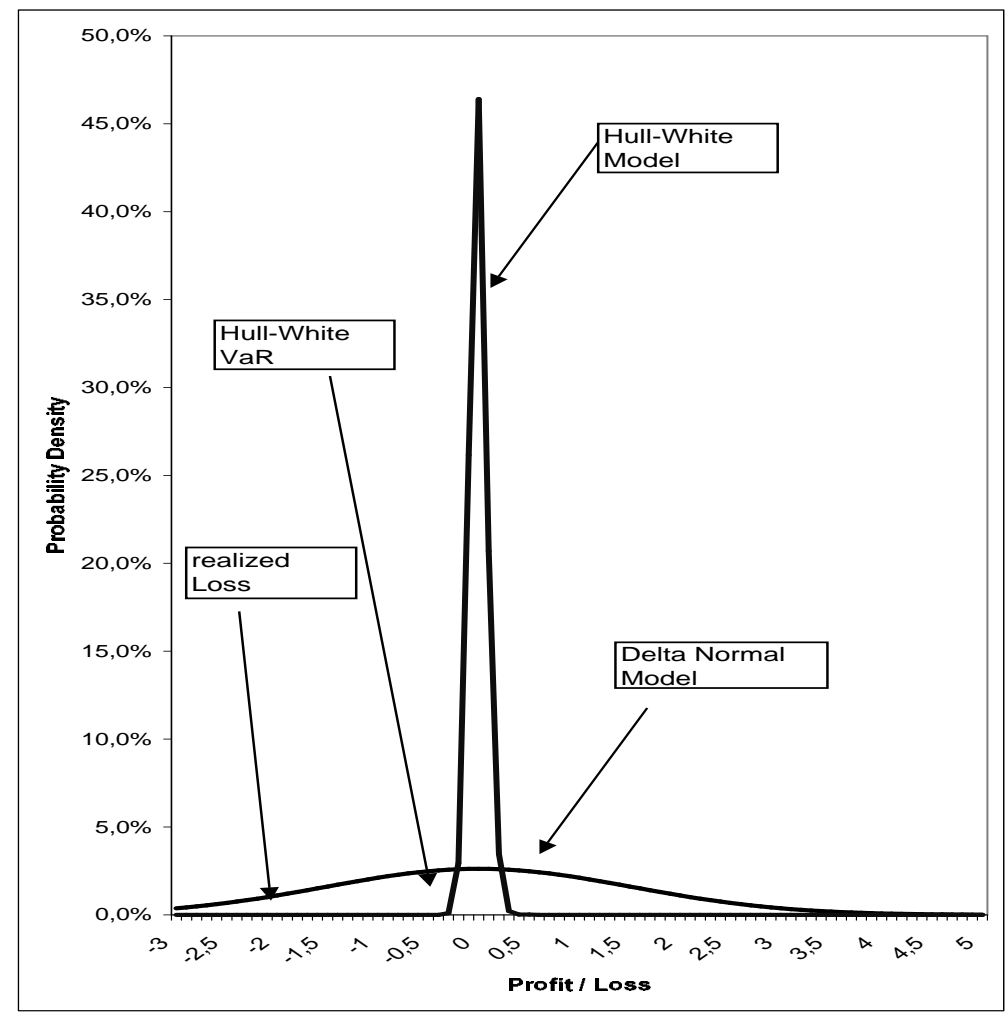

Carlo simulation will not include the observed scenario and the value-at-risk is underestimated. Figure 4 shows the density functions of the loss-distribution as calculated from the delta-normal and the Hull-White model respectively. For the reasons outlined above, the distribution is very narrow and centred around zero so that the realised loss is far beyond the $1 \%$-quantile.

For the much simpler Delta model, which on average yields much lower valueat-risk estimates, the worst loss is only a little bit less than six times as high as the value-at-risk. Thus when evaluating a value-at-risk model it is not only 
important to test for the percentage of failures, but also to have a closer look at the losses in the case of a failure. While a financial institution may have enough equity capital to survive a loss that exceeds the value-at-risk by a given amount, it is very unlikely, that an institution's capital is 12 times higher than its value-at-risk measure. 


\section{Results from the partitioned sample}

In table 3 we saw, that the out-of-sample pricing errors for both option pricing models increase with time to maturity and moneyness. Pricing errors are also smaller for calls than for puts. To get some idea, what value-at-risk models work better for a certain set of securities and if pricing errors have some impact on the performance of a value-at-risk model, the sample is partitioned according to a number of different criteria. The only test in this section is the proportion of failures test. Even though this test suffers from low statistical power, it is the test used by regulators to assess the performance of a financial institution's risk management.

\subsection{Puts vs. calls}

Table 11: Proportion of failures: puts vs. calls

\begin{tabular}{|l|r|r|r|r|}
\hline & \multicolumn{2}{|c|}{ Calls (6,516 obs.) } & \multicolumn{2}{|c|}{ Puts (3,635 obs.) } \\
\hline & failures & percent & failures & percent \\
\hline Delta & 199 & $3.05 \%$ & 148 & $4.07 \%$ \\
\hline Stock-Price MC & 118 & $1.81 \%$ & 104 & $2.86 \%$ \\
\hline Stock and Vola MC & $* 72$ & $1.10 \%$ & 73 & $2.01 \%$ \\
\hline Hull-White MC & 40 & $0.61 \%$ & 63 & $1.73 \%$ \\
\hline Basle & 1,112 & $17.07 \%$ & 621 & $17.08 \%$ \\
\hline
\end{tabular}

The sample consists of 6,516 observations for calls and 3,635 for puts. Table 11 shows, that all risk-measurement models have a lower proportion of failures for calls than for puts. This effect may be due to significant lower turnover and therefore wider bid-ask spreads in puts, as some market participants indicated. All models, that would not be rejected by the likelihood ratio test are marked by a star. For calls the acceptance region is between 51 and 81 and for puts it is between 26 and 48 failures, respectively. It is interesting to see, that while the 
Hull White model would be accepted, if tested on the whole sample, it would be rejected for calls, because it is too conservative and rejected for puts because it underestimates the value-at-risk. No model is able to pass the regulator's test for put options in this sample, but the Hull White model is closest. These findings are consistent with the results from section 4.2.1, where it was found, that pricing errors are larger for puts than for calls.

\subsection{Time to maturity}

Table 12: Proportion of failures: subsamples based on time to maturity

\begin{tabular}{|l|r|r|r|r|}
\hline & $\geq 1$ month (5272 obs.) & $<1$ month (4879 obs.) \\
\hline & failures & percent & failures & percent \\
\hline Delta & 243 & $4.61 \%$ & 104 & $2.13 \%$ \\
\hline Stock-Price MC & 175 & $3.32 \%$ & $* 47$ & $0.96 \%$ \\
\hline Stock and Vola MC & 93 & $1.76 \%$ & $* 52$ & $1.07 \%$ \\
\hline Hull-White MC & 81 & $1.54 \%$ & 22 & $0.45 \%$ \\
\hline Basle & 1,046 & $19.84 \%$ & 687 & $14.08 \%$ \\
\hline
\end{tabular}

Options in table 12 are grouped into options with a time to maturity of less then a month (4879 observations) and options with a longer maturity (5272 observations). The models pass the likelyhood ratio test, when they have between 36 and 63 and between 40 and 67 errors, respectively. No model is able to pass the test for options with maturities of more than one month, because they all underestimate the value-at-risk. Again, the Hull White model, which passes the test for the whole sample fails on both partitions of the sample, on the longer options, because the value-at-risk is too low, and on the shorter options, because the value-at-risk is too high. These findings are again consistent with the results from section 4.2.1. 


\subsection{Moneyness}

The relation of the option's strike price to the observed stock-price defines the moneyness of the option. For calls this ratio is defined as $m=\frac{\text { stock-price - strike-price }}{\text { strike-price }}$ and for puts: $m=\frac{\text { strike-price - stock-price }}{\text { strike-price }}$

Table 13: Proportion of failures: subsamples based on Moneyness

\begin{tabular}{|l|r|r|r|r|r|r|}
\hline & \multicolumn{2}{|c|}{ OTM (3367 obs.) } & \multicolumn{2}{c|}{ ATM (4813 obs.) } & \multicolumn{2}{c|}{ ITM (1971 obs.) } \\
\hline & failures & in \% & failures & in \% & failures & in \% \\
\hline Delta & 131 & $3.89 \%$ & 135 & $2.79 \%$ & 81 & $4.17 \%$ \\
\hline Stock-Price MC & 65 & $1.93 \%$ & 86 & $1.78 \%$ & 71 & $3.66 \%$ \\
\hline Stock and Vola MC. & 12 & $0.36 \%$ & $* 56$ & $1.16 \%$ & 77 & $3.97 \%$ \\
\hline Hull-White MC & $* 24$ & $0.71 \%$ & $* 47$ & $0.97 \%$ & 32 & $1.65 \%$ \\
\hline Basle & 528 & $15.68 \%$ & 707 & $14.60 \%$ & 498 & $25.66 \%$ \\
\hline
\end{tabular}

The options are divided into out of the money options (OTM) with a moneyness of less than -0.03 , at the money (ATM) options with $-0.03 \leq m \leq 0.03$ and in the money (ITM) options with a moneyness greater than 0.03. The respective acceptance regions are between 12 and 28 for ITM options, 36 and 62 for ATM options and between 24 and 46 for OTM options. The results are given in Table 13. All models perform worse for in the money options than for at and out of the money options. No model passes the test for all categories of moneyness, but the Hull-White model is very close. 


\section{Conclusion}

This paper evaluates the performance of different value-at-risk models for options using standard methods based on the Black-Scholes analysis and applied by most financial institutions and the more sophisticated Hull-White model for pricing options under stochastic volatility. The main findings of this study are:

Pricing models do not fit perfectly: In section 4.2.1 it was found, that there are large differences among pricing models. Since pricing models are necessary to predict option price movements when risk factors change, model selection is important. On average the Hull-White model fits much better, but the pricing errors vary more for specific options than with the Black-Scholes model. Both Option pricing and value-at-risk models work better with calls than with puts and with options having a shorter time to maturity.

Delta is not enough: The non-linear payoff-structure of options is important for risk management. Approximations with a linear relationship (the Delta approach) is significantly worse than the full-valuation approach, taking into account all non-linear relationships of option prices and risk factors.

Choose the risk factors properly: Adding volatility risk as a separate risk factor improves value-at-risk estimates significantly.

Testing value-at-risk models requires different perspectives: Regulators use the proportions of failure test, where the Hull White model would be the only accepted model. Using distribution tests however, all models would be rejected at a significance level almost equal to unity. In the interest of regulators and risk managers alike, other tests should be performed as well. Even though accepted by regulators, in the case of a failure, the complex 
Hull-White model would underestimate losses substantially. The results from the partitioned sample also show, that almost all models work better for calls than for puts, for options with a shorter time to maturity and for at or out of the money options. 


\section{References}

D-H Ahn, J. Boudoukh, M. Richardson, and R.F. Whitelaw. Optimal risk management using options. Journal of Finance, 54(1):359-375, 1999.

W. Aussenegg and Stefan Pichler. Empirical evaluation of simple models to calculate value-at-risk of fixed income instruments. AWG Working Paper \#22, 1997.

Basle Committee on Banking Supervision. The supervisory treatment of market risks, 1993.

Basle Committee on Banking Supervision. Amendment to the capital accord to incorporate market risks. http://www.bis.org/publ/bcbs24.pdf, 1996.

J. Berkowitz. Evaluating the forecasts of risk models. mimeo, 1998.

F. Black. Fact and fantasy in the use of options. Financial Analysts Journal 31, pages 36-41,61-72, 1975.

E. Böhmer and S. Sperlich. Risikomessung mit VaR für Portfolios: Diskussion und empirischer Vergleich verschiedener Berechnungsmethoden. Working paper, Humboldt University, Berlin, 1997.

M. Broadie and P. Glasserman. Simulation for option pricing and risk management. In C. Alexander, editor, Risk Management and Analysis, Vol. 1: Measuring and Modelling Financial Risk., pages 173-207. Wiley, 1998.

W. Bühler, M. Uhrig-Homburg, U. Walter, and T. Weber. Comparison of models for valuing interest-rate options. Journal of Finance, 54(1):269-305, 1999.

C. Corrado and T. Su. An empirical test of the hull-white option pricing model. Journal of Futures Markets, 18:363-378, 1998.

C. Crnkovic and J. Drachman. A universal tool to discriminate among risk measurement techniques. Risk, 9(9):138-143, 1996.

J. Danielsson and C.G. de Vries. Value-at-risk and extreme returns. mimeo, 1997.

G. de Raaij and B. Raunig. A comparison of value at risk approaches and their implication for regulators. Austrian National Bank working paper, 1999.

M. Dewatripont and J. Tirole. The Pridential Regulation of Banks. MIT Press, 1994.

F. Diebold and J. Lopez. Volatility models. Federal Reserve Bank of New York Research Paper \#9522, 1995. 
D. Duffie and J. Pan. An overview of value at risk. Journal of Derivatives 4, pages 7-49, 1997.

L. El-Jahel, W. Perraudin, and P. Sellin. Value at risk for derivatives. Journal of Derivatives, pages 7-26, 1999.

J. Engel and M. Gizycki. Conservatism, accuracy and efficiency: comparing value-at-risk models. mimeo, 1999.

A. Estrella. Taylor, black and scholes: Series approximations and risk management pitfalls. Presented at the Research Conference on Risk Measurement and Systemic Risk, Federal Reserve Board, Nov. 16, 1995.

W. Fallon. Calculating value-at-risk. Wharton Financial Institutions Center working paper 96-49, 1996.

K.A. Froot and J.C. Stein. Risk management, capital budgeting, and capital structure policy for financial institutions: an integrated approach. Journal of Financial Economics, 47:55-82, 1998.

D. Hendricks. Evaluation of value-at-risk models using historical data. Federal Reserve Bank of New York, Economic Policy review, 1996.

J. Hull and A. White. The pricing of options on assets with stochastic volatility. Journal of Finance, 42:281-300, 1987.

J. Hull and A. White. An analysis of the bias in option pricing caused by a stochastic volatility. In Advances in Futures and Options Research, volume 3. Greenwich CT: JAI Press, 1988.

J. Hull and A. White. Value at risk when daily changes in market variables are not normally distributed. Journal of Derivatives, pages 9-19, 1998.

P. Jackson, D.J. Maude, and W. Perraudin. Bank capital and value at risk. Journal of Derivatives, pages 73-89, 1997.

C. James. Raroc based capital budgeting and performance evaluation: A case study of bank capital allocation. Wharton Financial Institutions Center, Working Paper 96-40, 1996.

M.B. Jones and S.M. Schaefer. Non-linear value-at-risk. European Financial Review, forthcoming, 1999.

P. Jorion. Risk2: Measuring the risk in value at risk. Financial Analysts Journal, pages 47-56, 1996.

P. Jorion. Value at Risk : the new benchmark for controlling market risk. Irwin, 1997. 
R.C. Kimbal. Innovations in performance measurement in banking. New England Economic Review, pages 23-38, 1997.

R.C. Kimbal. Economic profit and performance measurement in banking. New England Economic Review, pages 35-53, 1998.

P.E. Kloeden and E. Platen. Numerical Solution of Stochastic Differential Equations. Springer, 1995.

P.H. Kupiec. Techniques for verifying the accuracy of risk measurement models. Journal of Derivatives, pages 73-84, 1995.

P.H. Kupiec. Risk capital and var. mimeo, 1999.

C. Lamoureux and W. Lastrapes. Forecasting stock return variances: Towards an understanding of stochastic implicit volatilities. Review of Financial Studies, 6:293-326, 1993.

A. Lehar, G. Strobl, and M. Scheicher. Implied vs. stochastic volatility, evidence from a small stock exchange. mimeo, 1998.

J.A. Lopez. Regulatory evaluation of value-at-risk models. Working paper 96-51, Wharton Financial Institutions Center, 1996.

C. Marshall and M. Siegel. Value at risk: Implementing a risk measurement standard. Journal of Derivatives, pages 91-111, 1997.

D. Marshall and S. Venkataraman. Bank capital standards for market risk: A welfare analysis. mimeo, 1997.

R.C. Merton and A.F. Perold. Theory of risk capital in financial firms. Journal of Applied Corporate Finance, 5:16-32, 1993.

F. Modigliani and M. Miller. The cost of capital, corporation finance and he theory of investment. American Economic Review, 48:261-297, 1958.

Morgan Guaranty Trust Company and Reuters Ltd. RiskMetrics-Technical Document, 4. edition, 1996. http://www.riskmetrics.com/text/research/techdocs/.

F. Palm. Garch models of volatility. In C.S. Maddala and C.R. Rao, editors, Handbook of Statistics, volume 14, pages 209-239. 1996.

S. Pichler and K. Selitsch. A comparison of analytical VaR methodologies for portfolios that include options. Working Paper, Technische Universitt Wien, 1999. 
W.H. Press, S.A. Teukolsky, W.T. Vetterling, and B.P. Flannery. Numerical Recipies in $C$ : the art of scientific computing. Cambridge University Press, second edition, 1992.

M. Pritsker. Evaluating value at risk methodologies: Accuracy versus computational time. Journal of Financial Services Research, 12:201-242, 1997.

W. Rhode. Old dogs, new tricks. Risk, 1998.

M. Rosenblatt. Remarks on a multivariate transformation. Annals of Mathematical Statistics, 23:470-472, 1952.

N. Stoughton and J. Zechner. Optimal capital allocation using RAROC and EVA. mimeo, 1999.

T. Styblo-Beder. Var. seductive but dangerous. Financial Analysts Journal, pages $12-24,1995$.

S.J. Taylor. Modeling Financial Time Series. Wiley, 1986.

T.C. Wilson. Value at risk. In C. Alexander, editor, Risk Management and Analysis, Vol. 1: Measuring and Modelling Financial Risk., pages 61-124. Wiley, 1998. 


\section{A Estimation of Hull-White paprameters and out of sample fit (aggregate basis)}

To make the parameter estimation computationally feasible, option prices are approximated using a Taylor series expansion as in Hull and White (1988), thereby assuming the volatility to be at its long run mean reversion level $V=-a / b$. The option prices of the Hull-White model $\left(C_{H W}\right)$ can then be approximated by:

$$
C_{H W}=C_{B S}+Q_{1} \rho \xi+Q_{2} \xi^{2}+Q_{3} \rho^{2} \xi^{2}
$$

where $C_{B S}$ denotes the corresponding Black-Scholes price, $V$ represents the instantaneous return Variance, $\xi$ is the volatility of volatility, $\rho$ represents the correlation between stock returns and variance changes, $b$ is the coefficient of mean reversion and $Q_{1}$ to $Q_{4}$ are defined as follows:

$$
\begin{aligned}
Q_{1}= & -\frac{1}{b^{2} \tau} V\left(1+\delta e^{\delta}\right) S \frac{\partial^{2} C}{\partial S \partial V} \\
Q_{2}= & \frac{1}{4 b^{3} \tau^{2}} V\left(e^{2 \delta}-4 e^{\delta}+2 \delta+3\right) \frac{\partial^{2} C}{\partial V^{2}} \\
Q_{3}= & -\frac{1}{b^{3} \tau} V\left(e^{\delta}(2-\delta)-(2+\delta)\right) S \frac{\partial^{2} C}{\partial S \partial V}+\frac{2}{b^{3} \tau^{2}} V\left(e^{\delta}(2-\delta)-(2+\delta)\right) \frac{\partial^{2} C}{\partial V^{2}}+ \\
& \frac{1}{2 b^{4} \tau^{2}} V^{2}\left(1+\delta-e^{\delta}\right)^{2} S \frac{\partial^{3} C}{\partial S \partial V^{2}}+\frac{1}{b^{4} \tau^{3}} V^{2}\left(1+\delta-e^{\delta}\right)^{2} S \frac{\partial^{3} C}{\partial V^{3}}
\end{aligned}
$$

Following Corrado and Su (1998), I estimate the required parameters each day by minimizing the sum of squared errors between observed and theoretical prices, that is

$$
\min _{V, \rho, \xi, b} \Sigma\left(C_{O B S}-C_{H W}\right)^{2}
$$

\section{A.1 Fit of the Hull-White vs. the Black-Scholes model}

Figure 5 shows the out of sample fit of the Hull-White model compared to the fit of the Black-Scholes model when using a single implied volatility, estimated by the method of Lamoureux and Lastrapes (1993) ${ }^{31}$, for a given day. The sums of the squared pricing errors are computed using the previous day's parameter

\footnotetext{
${ }^{31}$ Analogous to the estimation of the Hull-White model the method proposed by Lamoureux and Lastrapes (1993) seeks to minimize the sum of squared errors between observed and BlackScholes model prices by finding one implied volatility for each day.
} 
Figure 5: Out of sample performance of the Hull-White model and the BlackScholes model.

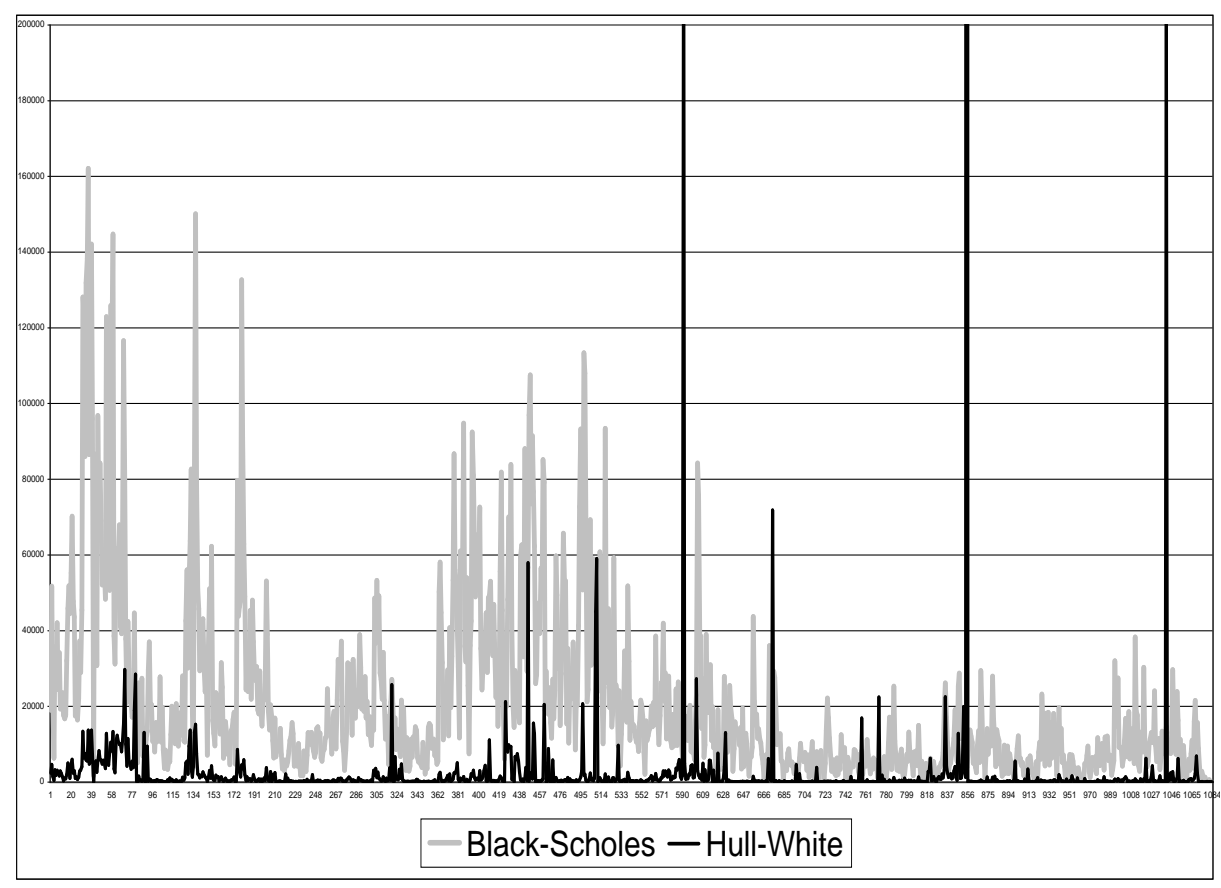

estimates. Here it is interesting to see, that generally the Hull-White model is superior to the Black-Scholes model, which also can be seen by computing the average sum of squared errors for the two models - 20,892.50 and 4,026.59 respectively. However there are days, where the performance of the Hull White model is extraordinarily bad.

\section{B Distribution test results}

This section shows the histograms of the percentiles of the realized losses under the distribution from the value-at-risk models. The classes in the histogram have a width of 0.05 and are plotted against the density of the uniform distribution. 


\section{EWMA-Delta}

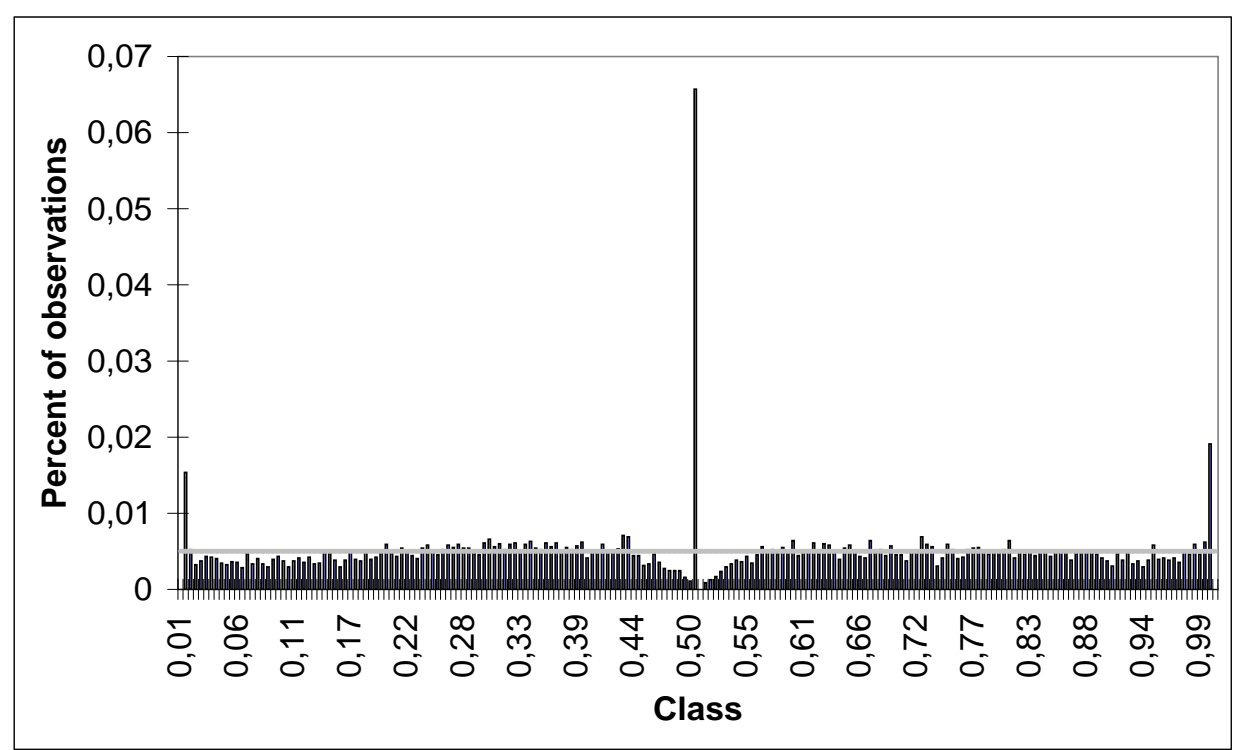

\section{EWMA - stock price MC}

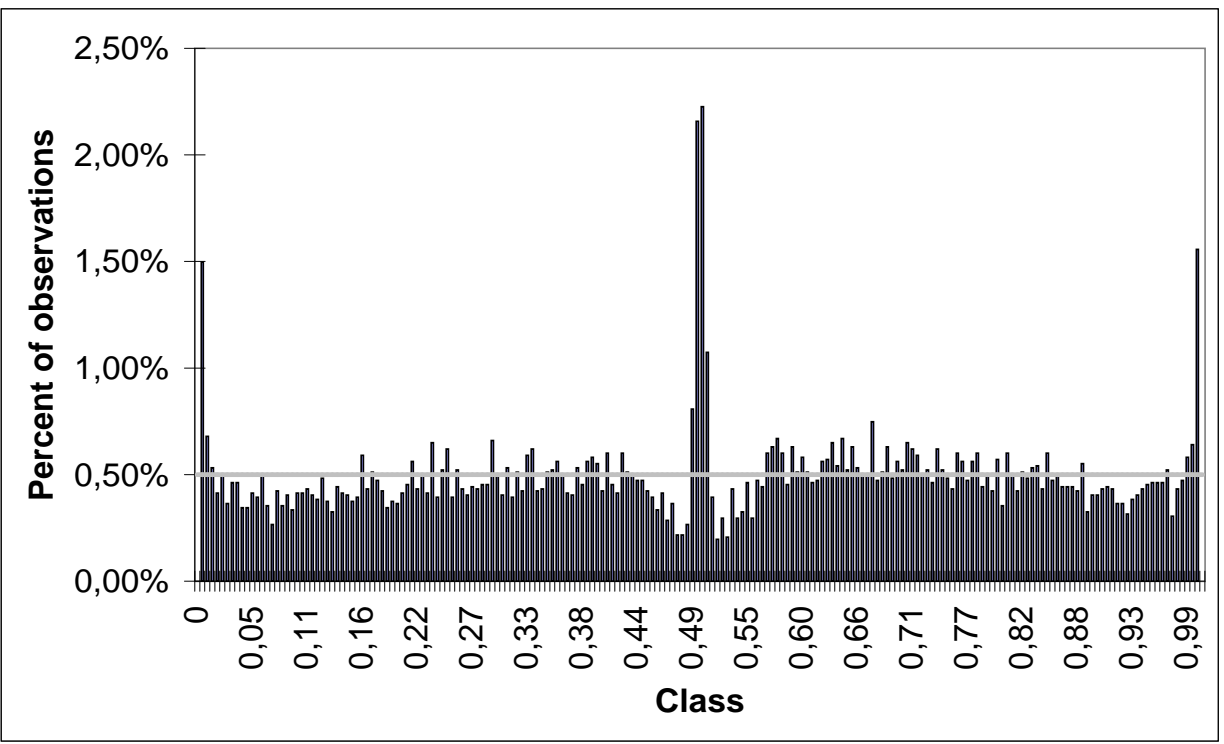




\section{EWMA - stock price and volatility MC}

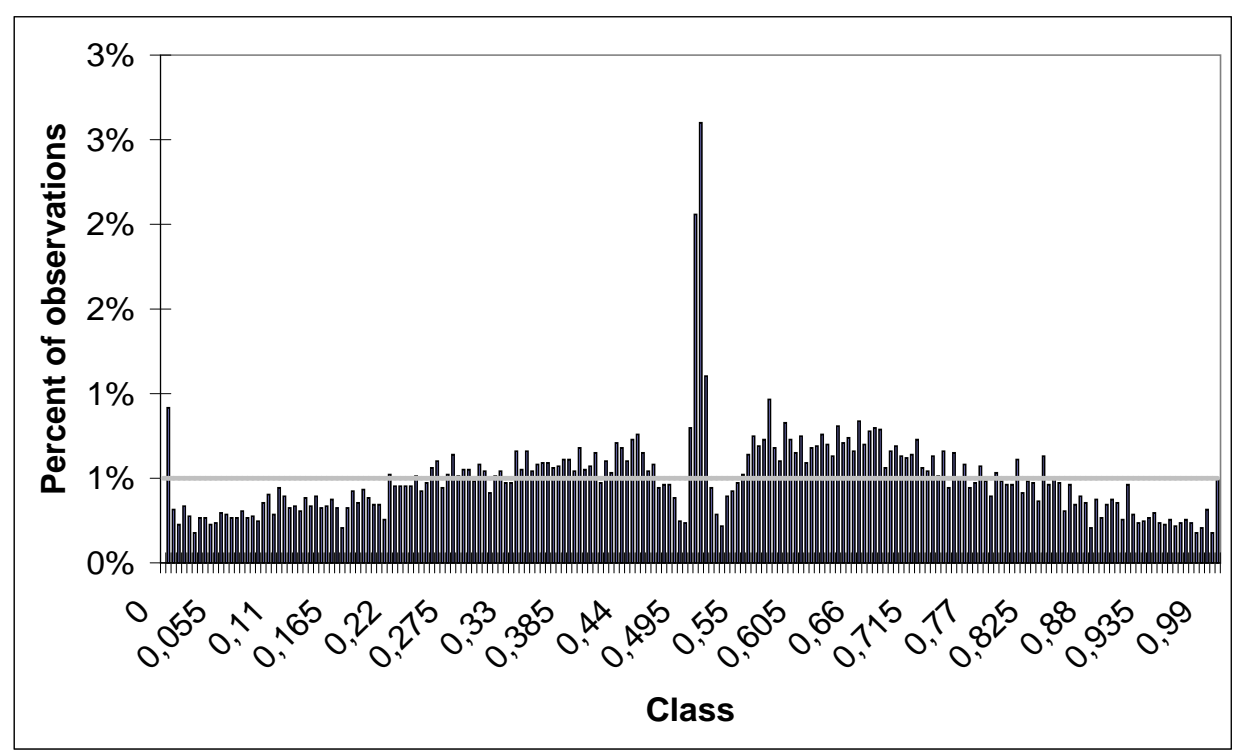

Hull-White Model

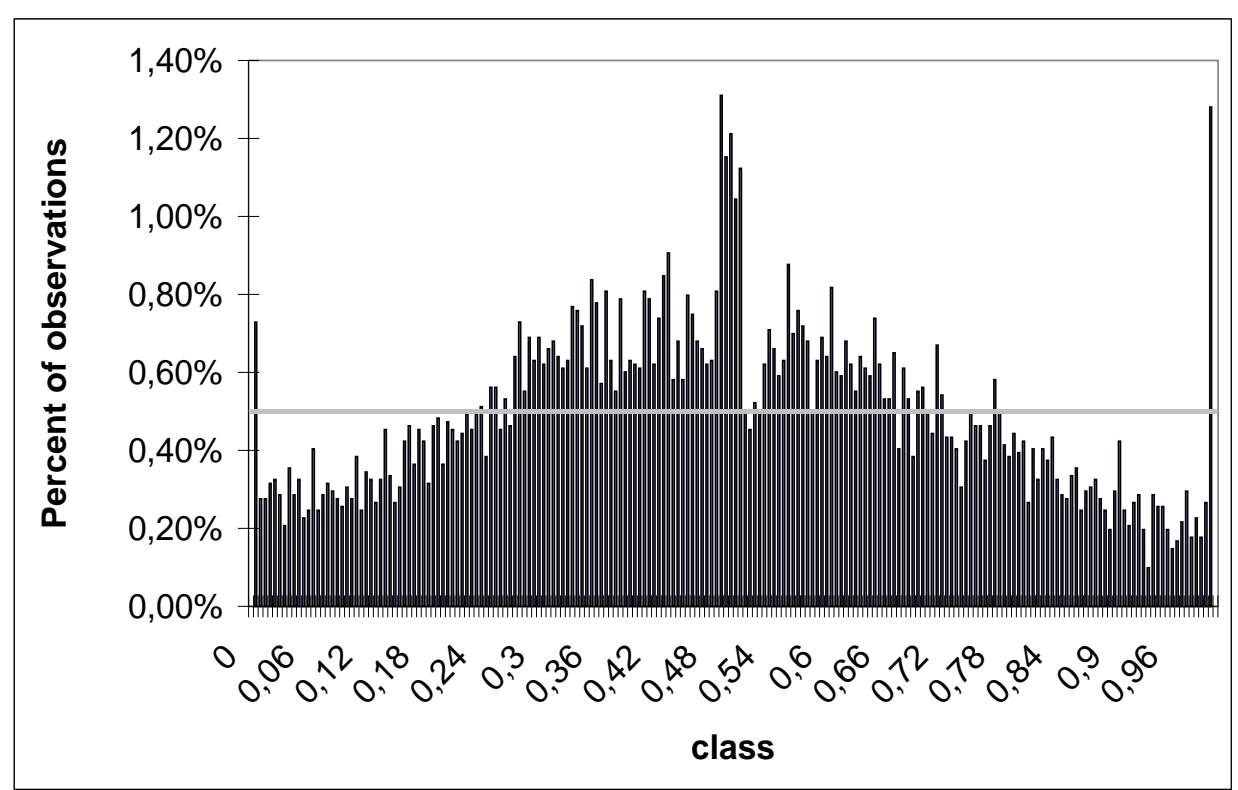

